\title{
Consecutive repetition of lordosis-kyphosis in silverside Atherina boyeri Risso, 1810 collected from a wild population in Homa Lagoon, Izmir, Turkey
}

\author{
Laith Jawad, Okan Akyol, Cemil Sağlam
}

Received - 06 April 2017/Accepted - 14 June 2017. Published online: 30 June 2017; @Inland Fisheries Institute in Olsztyn, Poland Citation: Jawad L., Akyol O., Sağlam C. 2017 - Consecutive repetition of lordosis-kyphosis in silverside Atherina boyeri Risso, 1810 collected from a wild population in Homa Lagoon, Izmir, Turkey - Arch. Pol. Fish. 25: 117-122.

\begin{abstract}
The incidence of severe consecutive repetition of lordosis-kyphosis involving three flexions was reported in a specimen of the atherinid fish Atherina boyeri Risso. The values for the angles lay between the lines passing through the sides of the vertebral column and enclosing the curvatures, and the depth of the curvatures of the angles was obtained. Also, the ratio of the vertebral column to the fish total length of deformed and normal specimens of this species was calculated. Possible causes for these anomalies are discussed.
\end{abstract}

Keywords: Anomalies, vertebral column, angles, abdominal vertebrae, caudal vertebrae

\section{Introduction}

Among the problems fishes encounter during their development are different types of aberrations in the skeletal system, which can influence morphology, growth, and the survival of individuals. In wild populations, skeletal anomalies are present, but they are relatively rare either because they are less frequent or

\section{Jawad [引]}

Flat Bush, Manukau, Auckland 2016, New Zealand

e-mail: laith_jawad@hotmail.com

O. Akyol, C. Sağlam

Ege University Faculty of Fisheries Urla, Izmir, Turkey because of the decreased viability of the abnormal fish in their natural habitat (Gavaia et al. 2009, Bogutskaya et al. 2011, Jawad et al. 2015a, 2016). Abnormalities can either be very severe so they affect the ability of the fishes, or slight, which do not affect survival and can occur as a result of various external and internal factors. The frequency and pattern of skeletal deformities form the basis of other studies such as the assessment and monitoring of environmental stresses or rearing conditions on fishes (Boglione et al. 2001, Ershov 2008).

Spinal deformities such as lordosis (ventral curvature) and kyphosis (dorsal curvature) have been described in many species both cultured and from wild populations (Afonso et al. 2000, Sfakianakis et al. 2004, Kranenbarg et al. 2005, Jawad et al. 2014a, Jawad et al. 2015a, 2015b). Lordosis is probably the most well studied axis anomaly in fishes. It can affect every region of the vertebral axis. It can be pre-haemal lordosis, which has been correlated significantly to the non-inflation of the swim bladder (Chatain 1994), but Boglione et al. (1995, 2009) and Andrades et al. (1996) did not find a similar correlation in some fish species; haemal lordosis, which is a quite frequent anomaly in fishes (Fjelldal et al. 2009, Koumoundouros 2010); and cranial (i.e. involving the anteriormost vertebrae); and caudal 
lordosis (involving the centra of the caudal peduncle), which are quite rare anomalies (Cataudella et al. 2011). Kyphosis is considered less common than lordosis (Boglione et al. 2013). As with lordosis, it can be found in the pre-haemal and haemal positions (Boglione et al. 1995). In the most severe cases, combinations of lordosis and kyphosis occur (Afonso et al. 2009).

Big scaled silverside, Atherina boyeri Risso, is an inshore-pelagic, schooling species found in shallow waters to depths of $5 \mathrm{~m}$. It is a euryhalinic fish that can thrive in hypersaline lagoons and fresh water. The spawning season is from March to September. Its demersal eggs have a diameter of 1.5-2 $\mathrm{mm}$. The species reaches sexual maturity at 5-7 months at a length of $3.5 \mathrm{~cm}$. It is very common in the eastern Mediterranean and also occurs in the Atlantic-Mediterranean region from southern England to Morocco (Golani et al. 2006).

In this study we carried out a morphological description of a case of lordosis-kyphosis in the teleost species $A$. boyeri taken from a wild population. This is the first report of this abnormality in this species from Turkey.

\section{Material and methods}

On December 29, 2015 one specimen of $A$. boyeri showing a continuous case of lordosis-kyphosis and another normal specimen were caught with an experimental beach seine from the marine side of Homa Lagoon on the coast of Izmir Bay (38³1'13’N-2650’32’E) at a depth of $1 \mathrm{~m}$ on a sandy bottom (Fig. 1). The specimens were fixed in 70\% ethanol and deposited in the fish collection of Ege University, Fisheries Faculty (ESFM-PIS/2015-015).

The skeletons of both the normal and abnormal specimens were examined using the mammography technique available at Ata Hospital, Izmir, Turkey. Siemens Mammomat 3000 nova mammography was used at an exposure time of $100 \mathrm{k} \mathrm{v}, 30$ mas, $3 \mathrm{sec}-$ onds. The length of the vertebral column from the anterior margin of the first vertebra to the posterior margin of the last vertebra was divided by fish total length to produce a ratio that was used to compare the abnormal with the normal fish. The angle of vertebral deformation was measured from the centre of the deformity, which in the present case was located in the caudal region, using a digital protractor. To assess the degree of abnormality in the anomalous individual, we measured the height of the curvature of the spinal column (HC). This corresponded to the distance between the tangent to the apical vertebra and a straight line which passed to the base of the two vertebrae limiting the curvature. The measurements were made with a digital caliper to the nearest 0.01 $\mathrm{mm}$. The depth of curvature (DC) was calculated with the following formula using the method by Louiz et al. (2007):

$$
D C=(H C / S L) \times 100(S L=\text { standard length fish })
$$

To describe vertebral shape changes independent of individual size differences, five ratios from seven vertebral measurements were calculated.

Length ratio $=$ dorsal length of the vertebra/ ventral length of vertebra

Width ratio $=$ anterior width of the vertebra/ posterior width of the vertebra

Height ratio $=$ dorsal height of the vertebra/ ventral height of the vertebra

Thickness ratio $=$ middle line width of the vertebra/posterior width of the vertebra Slenderness ratio $=$ dorsal length of the vertebra/ posterior width of the vertebra

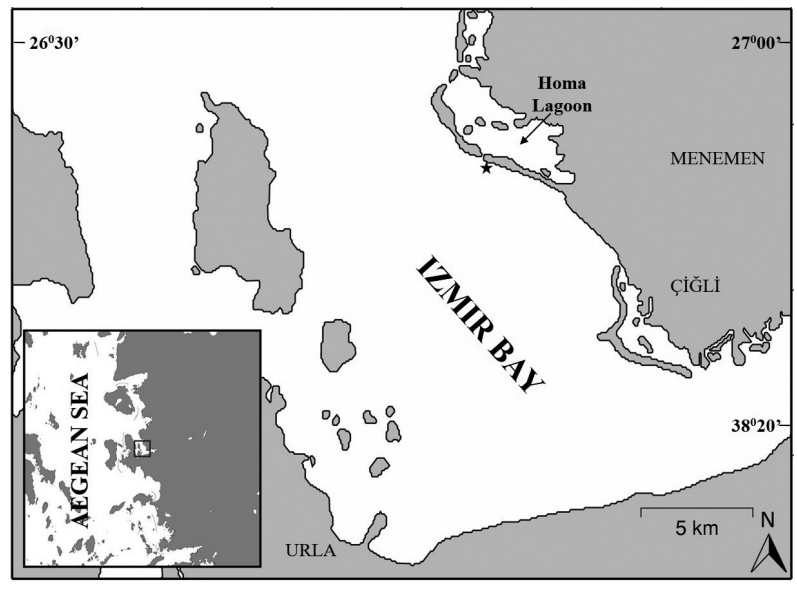

Figure 1. Map showing the sampling location. 
The purposes of the five ratios above are: length ratio for wedging along vertebral length; width ratio for wedging along the vertebral width; height ratio for distortion of the amphicoelous shape; thickness ratio for mid-centrum thickness; and slenderness ratio for ventral slenderness. All measurements were made by the same person and instrument in order to increase the precision of the measurements and reduce variability introduced by measurement error.

\section{Results}

The measurements of the abnormal fish were $65 \mathrm{~mm}$ total length (TL), $55 \mathrm{~mm}$ standard length (SL), and $20 \mathrm{~mm}$ head length (HL) compared to the normal specimen, which measured $82 \mathrm{~mm}$ TL, $70 \mathrm{~mm}$ SL, and $21 \mathrm{~mm}$ HL (Figs. 2a-b). Externally, the fish specimen showed two humps - the first was located between the dorsal fins and the second was located under the second dorsal fin. Besides the two humps, the body of the abnormal fish showed two concavities, one just posterior to the first dorsal fin and the other just anterior to the second dorsal fin (Fig. 2b).

The radiograph (Figs. 3a-b) showed that the whole thoracic vertebrae and the whole caudal vertebrae were involved in the arching upward and downward of the vertebral column. The first ascending arm of the arch was formed of abdominal vertebrae

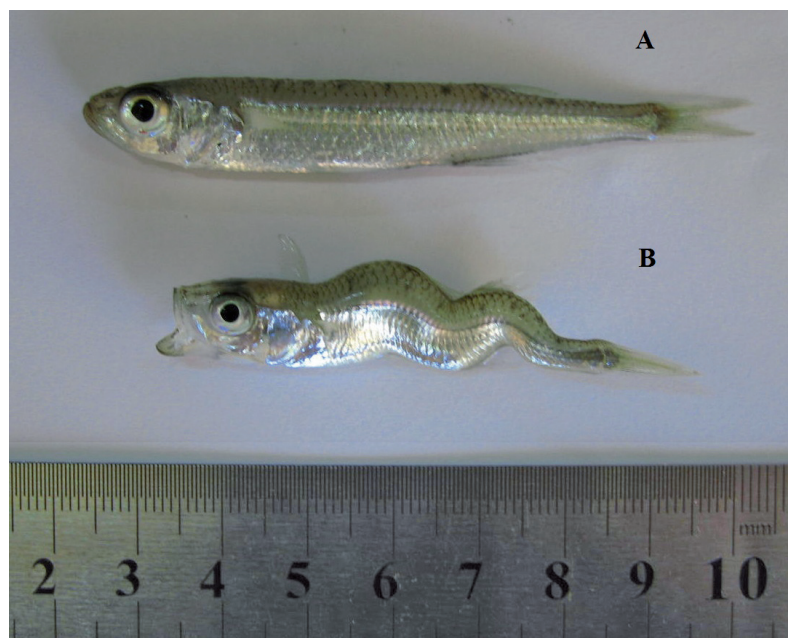

Figure 2. Atherina boyeri, a. normal specimen, $82 \mathrm{~mm}$ TL; b. abnormal specimen, $65 \mathrm{~mm}$ TL.
7-15, and the second ascending arch involved caudal vertebrae 9-15. The first descending arch involved abdominal vertebrae $1-7$, the second involved caudal vertebrae $2-8$, and the third descending arch involved caudal vertebrae 20-23. Abdominal vertebrae 15-17 and caudal vertebrae 16-19 were at the top of the first and second arches, respectively. Abdominal vertebrae $15-17$ and caudal vertebrae $16-19$ and 20-23 were at the bottom of the first, second, and third arches, respectively.

The ratio of vertebral column to fish TL in the deformed specimen was 0.4 , while it was 0.8 in the normal specimen. The value of angle "N1" lay between the arms of the first flexion and was $135^{\circ}$, and the value of angle "N2" lay between the arms of the second flexion and was $94^{\circ}$. The depth of the curvature of angle "N1" was $8.9 \mathrm{~mm}$, and the depth of the curvature of angle "N2" was $8.5 \mathrm{~mm}$ (Fig. 3b).

The five ratios calculated appeared to be affected by the position of the vertebra and the curvature of the vertebral column. The vertebrae at the top of the arches exhibited increased height on the ventral side (0.027-0.029) and reduced height on the dorsal side (1.130-1.026) (Fig. 3b). Vertebrae 8 and 9 were wedged (1.345-1.365) (reduced ventral length relative to dorsal length). The ascending vertebrae had reduced midline widths (0.011-0.013). Similarly, the descending vertebrae exhibited the same features, but to a lesser degree than those in the ascending arch. The amphicoelous centra of these vertebrae were also distorted such that the height was increased on the dorsal side (0.004-0.006).

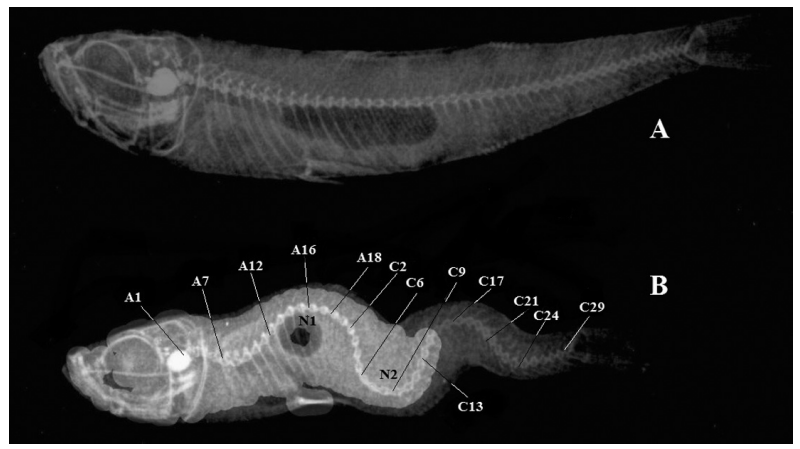

Figure 3. Mammography of Atherina boyeri, a. normal specimen, $82 \mathrm{~mm}$ TL; b. abnormal specimen, $65 \mathrm{~mm}$ TL. 
Slenderness and thickness were less in ascending vertebrae (0.001-0.003) (Fig. 3b).

\section{Discussion}

A substantial amount of current literature is available on wild fish anomalies (Divananch et al. 1996, Jawad et al. 2013a, 2013b, Jawad and Liu 2015) that describes the causes of different deformities. They include both genetic (Ishikawa 1990) and epigenetic factors as possible sources of such aberrations (Fjelldal et al. 2009), as well as environmental factors such as temperature, light, salinity, $\mathrm{pH}$, low oxygen concentrations, inadequate hydrodynamic conditions, and parasites (Chatain 1994, Gavaia et al. 2009). It is possible that the deformed $A$. boyeri specimen had encountered unfavourable environmental factors that might have caused this type of vertebral abnormality. Since the specimen of $A$. boyeri was an adult, the deformation was not fatal, but it certainly affected mobility in some way. Except for the repetitive lordotic-kyphotic curvatures, the remaining parts of the fish body were apparently in perfect condition.

The morphological changes of lordosis and kyphosis exhibited in the specimen examined were related to anterior-posterior (i.e., cranial-caudal) compression along the spine. Structural indications were present in the $\mathrm{x}$-ray showing that the normal amphicoelous (hour-glass) shape of vertebrae was distorted so that vertebral height was reduced on the convex side and was greater on the concave side of the curvature. Additionally, the vertebrae at the approximate apex of the curvature (lordotic vertebra number) were wedged so that the length on the concave side of the curve was reduced relative to the convex length. The midline width was also significantly reduced in some vertebrae. Similar changes were observed in Poecilia reticulata Peters by Gorman et al. (2010). They suggest that the observed changes in vertebral bone structure could be due to either (1) the distortion of normal vertebral shape, or (2) the active remodeling of vertebral osteoid bone as a consequence of extrinsic forces. The second cause was described in animal models with induced curvature in a number of teleost species (Huysseune et al. 2000, Kranenbarg et al. 2005). Several studies demonstrate that bone modeling can be affected by elevated water oxygen levels through the impact on bone mineral composition (Helland et al. 2005, Gil-Martens et al. 2006). In Izmir Bay, the water oxygen level is low (Bizsel and Uslu 2000, Kontas et al. 2004), with high variation in water temperature (Odabasi et al. 2008). In such an environment, hypoxia can develop and cause teratogenic conditions for the musculoskeletal system during embryonic development and the first larval stage. Hypoxia can also provoke cell apoptosis, a key process in these stages (Shin et al. 2004).

The consecutive presence of lordosis and kyphosis (L-K) in the present specimen could have been genetically determined. This is suggested by Afonso et al. (2000) in a similar case they examined in Sparus aurata. In the present paper, although the cause of lordosis-kyphosis was not investigated, the hypothesis of genetic involvement could not be excluded and indicated that a vertebral deformity could consist of a consecutive repetition of lordosis and kyphosis (L-K syndrome).

Izmir Bay is reported to have a high level of pollution in trace metals (Kucuksezgin et al. 2006, Pekey 2006, Kucuksezgin et al. 2011). Trace metals can decrease collagen synthesis, cause protoplasmic poisoning, and change the integrity of bones (Luh et al. 1973, Bhatnager and Hussain 1977, Iguchi and Sano 1982). Economic outcomes of vertebral deformities are important in terms of reduced weight and more importantly from the significantly reduced value per $\mathrm{kg}$ of selling fish. Therefore, further efforts to improve the management of fisheries industries should be made to explore the various etiological causes of deformities before further critical choices are made.

Author contributions. L.J. wrote the manuscript and follow up the process of the publication, O.A. and C.S. have designed and performed the collection, measurements and photography. 


\section{References}

Afonso J.M., Astorga N., Navarro A., Montero D., Zamorano M.J., Izquierdo M. 2009 - Genetic determination of skeletal deformities in gilthead seabream (Sparus aurata L.) In: IAFSB 2009 Book of abstracts, p. 90. Communication Interdisciplinary Approaches in Fish Skeletal Biology, 27-29 April 2009, Tavira, Algarve, Portugal.

Afonso J.M., Montero D., Robaina L., Astorga N., Izquierdo M.S., Ginés R. 2000 - Association of a lordosis-scoliosis-kyphosis deformity in gilthead seabream (Sparus aurata) with family structure - Fish Physiolol. Biochem. 22: 159-163.

Andrades J.A., Becerra J., Fernández-Liebrez P. 1996 - Skeletal deformities in larval, juvenile and adult stages of cultured gilthead sea bream (Sparus aurata L.) Aquaculture 141: 1-11.

Bhatnager R. S., Hussain M. A. 1977 - Interference with steps in collagen synthesis: a test for pulmonary toxicity of environmental agents $-\mathrm{In}$ : Proceedings of the $4^{\text {th }}$ Joint Conference of Sensing Environmental Pollutants, Washington DC: American Chemical Society: 527-531.

Bizsel N., Uslu O. 2000 - Phosphate, nitrogen and iron enrichment in the polluted Izmir Bay, Aegean Sea - Mar. Environ. Res. 49: 101-122.

Boglione C., Gagliardi G., Scardi M., Cataudella S. 2001 Skeletal descriptors and quality assessment in larvae and post-larvae of wild-caught and hatchery-reared gilthead sea bream (Sparus aurata L. 1758) - Aquaculture 192: $1-22$.

Boglione C., Gavaia P., Koumoundouros G., Gisbert E., Moren M., Fontagne S. 2013 - Skeletal anomalies in reared European fish larvae and juveniles. Part 1: normal and anomalous skeletogenic processes - Rev. Aquacult. 5: 99-120.

Boglione C., Marino G., Fusari A., Ferreri A., Finoia M.G., Cataudella S. 1995 - Skeletal anomalies in Dicentrarchus labrax juveniles selected for functional swimbladder - ICES marine Sei. Symp. 201: 163-169.

Boglione C., Marino G., Giganti M., Longobardi A., De Marzi P., Cataudella S. 2009 - Skeletal anomalies in dusky grouper Epinephelus marginatus (Lowe 1834) juveniles reared with different methodologies and larval densities Aquaculture 291: 48-60.

Bogutskaya N.G., Zuykov M.A., Naseka A.M., Anderson E.B. 2011 - Normal axial skeleton structure in common roach Rutilus rutilus (Actinopterygii: Cyprinidae) and malformations due to radiation contamination in the area of the Mayak (Chelyabinsk Province, Russia) nuclear plant - J. Fish Biol. 79: 991-1016.

Cataudella S., Palamara E., Ferrante I., Prestinicola L., Velluti F., Costa C. 2011 - Validation of morpho-physiological indicators of the productive chain of (Dicentrarchus labrax) and gilthead seabream (Sparus aurata), and reference modeling for an expert system - Final report Research Project 7C144 Italian Ministry for Agricultural and Forestry Politics (in Italian with extended abstract in English).

Chatain B. 1994 - Abnormal swimbladder development and lordosis in sea bass (Dicentrarchus labrax) and sea bream (Sparus auratus) - Aquaculture 119: 371-379.

Divanach P., Boglione C., Menu B., Koumoundouros G., Kentouri M., Cataudella S. 1996 - Abnormalities in finfish mariculture: an overview of the problem, causes and solutions - In: Seabass and Seabream Culture: Problems and Prospects (Eds) B. Chatain, M. Saroglia, J. Sweetman, P. Lavens, European Aquaculture Society, Oostende, Belgium: 45-66.

Fjelldal P.G., Hansen T., Breck O., Sandvik R., Waagbø R., Berg, A., Ørnsrud R. 2009 - Supplementation of dietary minerals during the early seawater phase increases vertebral strength and reduce the prevalence of vertebral deformities in fast-growing under-yearling Atlantic salmon (Salmo salar L.) smolt - Aquacult. Nutr. 15: 366-378.

Gavaia P.J., Domingues S., Engrola S., Drake P., Sarasquete C., Dinis M.T., Cancela M.L. 2009 - Comparing skeletal development of wild and hatchery-reared Senegalese sole (Solea senegalensis, Kaup 1858): evaluation in larval and postlarval stages - Aquac. Res. 40: 1585-1593.

Golani D., Öztürk B., Başusta N. 2006 - Fishes of the Eastern Mediterranean - Turkish Marine Research Foundation (Publication No. 24), Istanbul, Turkey.

Gorman K. F., Handrigan G. R., Jin G., Wallis R., Breden F. 2010 - Structural and micro-anatomical changes in vertebrae associated with idiopathic-type spinal curvature in the curveback guppy model - Scoliosis and Spinal Disorders 5: 1-13

Helland S., Refstie S., Espmark A., Hjelde K., Baeverfjord G. 2005 - Mineral balance and bone formation in fast-growing Atlantic salmon parr (Salmo salar) in response to dissolved metabolic carbon dioxide and restricted dietary phosphorus supply - Aquaculture 250: 364-376.

Huysseune A. 2000 - Skeletal system - In: The Laboratory fish (Ed.) G.K. Ostrander, Academic Press, London: 307-317.

Iguchi H., Sano S. 1982 - Effect of cadmium in the bone collagen metabolism of rat - Toxicol. Appl. Pharm. 62: 126-136.

Ishikawa Y. 1990 - Development of caudal structures of a morphogenetic mutant (Da) in the teleost fish, medaka (Oryzias latipes) - J. Morphol. 205: 219-232.

Jawad L.A. 2014 - Vertebral abnormalities in the oriental sole Brachirus orientalis (Bloch \& Schneider, 1801) (Teleostei, Hetrosomata) collected from the coasts of Muscat City on the Sea of Oman - Bollettino del Museo 
Civico di Storia Naturale di Verona, Botanica Zoologia 38: 193-196.

Jawad L., Liu J. 2015 - First record of vertebral anomalies in some members of the genus Pampus (Family: Stromateidae) collected from Guangdong, China and from the Kii Peninsula, Honshu Island, Japan - Mar. Biodivers. Rec. 8: 1-5.

Jawad A.L.J., Al-Shogebai S., Al-Mamry J.M. 2013a A reported case of malpigmentation in the spangled emperor Lethrinus nebulosus (Osteichthyes: Lethrinidae) collected from the arabian sea coasts of Oman Thalassia Salent. 35: 29-36.

Jawad L., Sadighzadeh Z., Salarpouri A., Aghouzbeni S. 2013b - Anal Fin Deformity in the Longfin Trevally, Carangoides armatus - Korean J. Ichthyol. 25: 169-172.

Jawad L.A., Al-Faisal A.J., Al-Mukhtar M. 2015a - A case of vertebral coalescence in Lucibarbus xanthopterus (Heckel, 1843) (Pisces: Cyprinidae) obtained from the lower reaches of Mesopotamia - Travaux du Muséum National d'Histoire Naturelle "Grigore Antipa" 57: 127-132.

Jawad L.A., Wallace A., Dyck W. 2015b - Documentation of the case of hyperostosis in the silver bream, Pagrus auratus (Forster, 1801) sampled from waters around New Zealand - Boletim do Instituto de Pesca, Săo Paulo 41: 1043-1047.

Jawad L.A., Fjelldal P.G., Hansen T. 2016 - First report on vertebral abnormality in the fivebeard rockling Ciliata mustela (Linnaeus, 1758) (Osteichthyes: Lotidae) from Masfjorden, Western Norway - Mar. Biodivers. 1: 1-5.

Kontas A., Kucuksezgin F., Altay O., Uluturhan E. 2004 Monitoring of eutrophication and nutrient limitation in the Izmir Bay (Turkey) before and after Wastewater Treatment Plant - Environ. Int. 29: 1057-1062.

Koumoundouros G. 2010 - Morpho-anatomical abnormalities in Mediterranean marine aquaculture - In: Recent Advances in Aquaculture Research (Ed.) G. Koumoundouros, Transworld Research Network, Kerala, India: 125-148.
Kranenbarg S., Waarsing J.H., Müller M., Weinans H., van Leeuwen J.L. 2005 - Lordotic vertebrae in sea bass (Dicentrarchus labrax L.) are adapted to increased loads - J. Biomech. 38: 1239-1246.

Kucuksezgin F., Kontas A., Uluturhan E. 2011 - Evaluations of heavy metal pollution in sediment and Mullus barbatus from the Izmir Bay (Eastern Aegean) during 1997-2009 - Mar. Pollut. Bull. 62: 1562-1571.

Kucuksezgin F., Kontas A., Altay O., Uluturhan E., Darilmaz E. 2006 - Assessment of marine pollution in Izmir Bay: Nutrient, heavy metal and total hydrocarbon concentrations - Environ. Int. 32: 41-51.

Luh M.D., Baker R.A., Henley D.E. 1973 - Arsenic analysis and toxicity - A review - Sci. Total Environ. 2: 1-12.

Martens G.L., Witten P.E., Fivelstad S., Huysseune A., Sævareid B., Vikeså V., Obach A. 2006 - Impact of high water carbon dioxide levels on Atlantic salmon smolts (Salmo salar L.): Effects on fish performance, vertebrae composition and structure - Aquaculture 261: 80-88.

Odabasi M., Cetin B., Demircioglu E., Sofuoglu A. 2008 Air-water exchange of polychlorinated biphenyls (PCBs) and organochlorine pesticides (OCPs) at a coastal site in Izmir Bay, Turkey - Mar. Chem. 109: 115-129.

Pekey H. 2006 - The distribution and sources of heavy metals in Izmit Bay surface sediments affected by a polluted stream - Mar. Pollut. Bull. 52: 1197-1208.

Shin D.H., Lee E., Kim J-W., Kwon B-S., Jung M-K., Jee Y-H., Kim J., Bae S-R., Chang Y-P. 2004 - Protective effect of growth hormone on neuronal apoptosis after hypoxia-ischemia in the neonatal rat brain - Neurosci. Lett. 354: 64-68.

Sfakianakis D.G., Koumoundouros G., Divanach P., Kentouri M. 2004 - Osteological development of the vertebral column and of the fins in Pagellus erythrinus (L. 1758). Temperature effect on the developmental plasticity and morpho-anatomical abnormalities - Aquaculture 232: 407-424.

Yershov P.N. 2008 - The vertebral abnormalities in eelpout Zoarces viviparus (Linnaeus, 1758) (Pisces, Zoarcidae) Proceedings of the Zoological Institute RAS 312: 74-82. 